This item was submitted to Loughborough's Research Repository by the author.

Items in Figshare are protected by copyright, with all rights reserved, unless otherwise indicated.

\title{
Seeking relational information sources in the digital age: a study into information source preferences amongst family and friends of those with dementia
}

\section{PLEASE CITE THE PUBLISHED VERSION}

https://doi.org/10.1177/1471301218786568

\section{PUBLISHER}

SAGE Publications

\section{VERSION}

AM (Accepted Manuscript)

\section{PUBLISHER STATEMENT}

This paper was accepted for publication in the journal Dementia and the definitive published version is available at https://doi.org/10.1177/1471301218786568. Users who receive access to an article through a repository are reminded that the article is protected by copyright and reuse is restricted to non-commercial and no derivative uses. Users may also download and save a local copy of an article accessed in an institutional repository for the user's personal reference.

\section{LICENCE}

CC BY-NC-ND 4.0

\section{REPOSITORY RECORD}

Allen, Frances, Rebecca Cain, and Caroline Meyer. 2018. "Seeking Relational Information Sources in the Digital Age: A Study into Information Source Preferences Amongst Family and Friends of Those with Dementia". Loughborough University. https://hdl.handle.net/2134/12625553.v1. 
Seeking relational information sources in the digital age: A study into information source preferences among family and friends of those with dementia.

Frances Allen BSc

WMG, University of Warwick, Coventry. CV4 7AL

F.Allen@warwick.ac.uk

Dr Rebecca Cain

Loughborough Design School, Loughborough University, Epinal Way, Loughborough LE11 3TU

R.Cain@lboro.ac.uk

Professor Caroline Meyer

WMG, University of Warwick, Coventry. CV4 7AL

C.Meyer@warwick.ac.uk

\section{Conflict of interest}

The author(s) declared no potential conflicts of interest with respect to the research, authorship, and/or publication of this article 


\begin{abstract}
Despite an increasing number of sources providing information and advice about dementia, those living with the condition feel inadequately informed. The reasons for this remain unclear. This study has three aims: to identify where people with dementia and their carers currently access dementia-related information from; to determine how accessible, credible and comprehensible people with dementia and their carers consider the available sources of information; and to determine how people with dementia and their carers would like to receive information. An online or postal survey was completed by 171 female and 41 male participants with a close family member or friend with dementia. Accessibility above quality held the greatest influence over an individual's use of an information source. Participants preferred relational sources such as healthcare professionals as these were able to give individualised information, yet these were poorly accessible and lacked dementia specific knowledge. Therefore, individuals used non-relational sources such as the internet. However, increased use of the internet was linked to feeling overwhelmed by information. It was not the end result of the information search but the effort taken to reach the information that influenced participant's perception of information gathering. Future research should look at ways of designing and providing accessible information sources that act and feel like relational contact.
\end{abstract}




\section{SEEKING RELATIONAL INFORMATION SOURCES IN THE DIGITAL AGE: A STUDY INTO INFORMATION SOURCE PREFERENCES AMONG FAMILY AND FRIENDS OF THOSE WITH DEMENTIA}

\section{BACKGROUND}

A number of different information channels are available to those seeking advice about dementia. Specifically, traditional sources (such as health and social care professionals, newspapers and printed media) can now be used in conjunction with more modern methods, such as the internet and social media (e.g., Altizer et al. 2014; Sweet et al. 2013; Anderson et al. 2009; Dutta-Bergman 2004). Despite the number of different information sources available, family and friends of those with dementia often do not feel as well informed about the condition as they would like (e.g., Allen et al. 2017; Washington et al. 2011).

To begin to address this, the UK National Institute for Health and Care Excellence (NICE) has written quality standards which state that all those who are newly diagnosed with dementia and their carers should receive written and verbal information about the condition, local support services and treatment (National Institute for Health and Care Excellence, 2010). However, this quality standard does not prescribe the breadth of information that this advice should contain and does not address the provision of information later in the disease process.

One issue affecting how information is provided by health care professionals is how accessible they are to patients and carers. Accessibility improves the ability of an information source to provide information in a timely way and sources need to be adaptable to the changing needs of both carers and people with dementia (Robinson et al., 2009; Suhonen, Stolt, Koskenniemi, \& Leino-Kilpi, 2015; Washington et al., 2011).

There are two ways in which information can be received or sought. Passive information being received without actively being sought (e.g., seeing something on the television or in a newspaper which was not read for the purpose of finding information). While, active 
information is that which requires the individual to purposefully seek it out (Johnson \& Case, 2012).

The attributes which relate to the type of information required can influence those actively looking for information on health topics. One such attribute is whether the information required is tacit (relating to feelings and experiences and is not easily written down or described) or explicit (relates to procedure and fact, more easily written down)Polanyi 1983). Online forums and face to face support groups are particularly good for receiving tacit knowledge by allowing the dissemination of personal experiences from a wide population (Craig \& Strivens, 2016; Foster, 2016).

This type of information, obtained directly from another person, is known as a relational information source. Conversely, non-relational information does not require human connection (e.g. published leaflets or static internet pages) and therefore tend to be more accessible (Lu \& Yuan, 2011; Zimmer, Henry, \& Butler, 2007). Relational information sources which, by definition contain interpersonal elements are important in healthcare provision where empathy and ability to give emotional support are regarded as helpful to patients regardless of the quality of information they give (Pecchioni \& Sparks, 2007; Pettigrew, 2000).

The two most influential characteristics in the choice of information source are; Accessibility (i.e., how easily an information source can be reached) and Quality (accuracy, usability and comprehensibility) (Lu \& Yuan, 2011; Zimmer et al., 2007). Accessibility is important because people may choose a lower quality, but easily accessible, information source over a high quality but inaccessible one (Zimmer et al., 2007). The accessibility of a source of information for people caring for a loved one with dementia is influenced by how much time it takes to obtain useful information (Harland \& Bath, 2008). 
Information use rarely fits into the distinct categories described previously. For example, online social media groups for dementia can move from being non-relational and passive, providing explicit information to become relational, active and able to address more tacit knowledge. This is achieved by individuals initiating their own inter-user contacts outside of the online environment (Craig \& Strivens, 2016). This contact was used for clarifying comprehension of information provided by health practitioners and for gaining insight into the perspectives of other users with dementia (Nagler et al. 2010). There is a lack of clarity as to where carers currently look for information and what influences their choice. It has been hypothesised that carers for people with dementia may exhibit different preferences depending on their information need, but this has not been empirically tested (Harland \& Bath 2008). Additionally Media Complementarity Theory postulates that individuals do not swap completely to new forms of media when they become available, but rather use them to complement those already in use (Dutta-Bergman, 2004).

As a source of information for people with dementia and carers, the internet is accessible and offers a broad range of advice (Kort S.M. \& van Hoof 2014). However, there is a wide discrepancy in the quality of the advice offered regarding dementia online. When evaluated, websites which appeared at the top of the most common dementia information searches were not those which gave the most evidence- based information (Anderson et al. 2009).

Due to the breadth and varying quality of online content, planning an internet search strategy is a complex task which requires good levels of cognition, memory and recall. This is particularly pertinent for older people who lack long term experience with the internet and therefore lack the habitual skills of those who are more familiar with the technology. (Sharit, Hernandez, Czaja, \& Pirolli, 2008). Yet, internet use amongst people over 65 is growing. Statistics also show that $71 \%$ of adults over 65 had used the internet in the preceding three 
months. (Office for National Statistics, 2015) although, age has consistently been shown to be a significant predictor of information source use (Bishop et al., 2009; Fischer et al, 2014).

In summary, individuals close to those with dementia feel that they do not receive enough information to meet their needs. This is despite a wide range of information sources being available. However, it remains unclear where people with dementia and their carers currently seek information from and what their preferences of information delivery are. Additionally, it is unclear whether the use of information sources is affected by perceived usability. Therefore, this study had three aims. First, to identify where family and friends of those with dementia currently access dementia-related information from. Second, to determine how accessible, credible and comprehensible people with close friends and family with dementia consider the available sources of information. Third, to determine how people close to those living with dementia would like to receive information.

\section{Methodology}

\section{Participants / Recruitment}

Recruitment was conducted using the 'Join dementia research' (JDR) database run by the National Institute for Health Research. JDR allows people who are interested in participating in dementia research to register their interest via the JDR website, healthcare professional or at sign up stations based in healthcare settings. It is also possible to sign up close family members and friends with their permission. The JDR register records were searched using the inclusion criteria against the information provided by volunteers. All matched participants were screened by the researcher and those who continued to meet the inclusion criteria were then contacted and invited to participate.

Alongside JDR, secondary recruitment was via posts on social media (Twitter and Facebook), a post on the Talking Point online dementia discussion forum and posters displayed at a variety 
of settings including libraries and public notice boards in shopping centres and supermarkets. Prospective participants were directed to either the URL for the questionnaire or to contact the chief investigator for a printed participant pack as per their preference.

To be included in the study, a participant needed to have a close family member or friend with dementia who lives at home, be over 18 and be an English speaker.

\section{Measures}

A study specific questionnaire was developed. The questionnaire underwent a process of design including the formation of questions stemming from data collected from a previous study (Allen et al., 2017) and literature. Questions regarding computer, internet and passive information use were adapted from the U.S. Health Information National Trends Survey (HINTS) (National Institutes of Health \& Services, 2014) with multiple choice answers updated for a UK demographic.

Multiple choice, likert scale and open questions were used to ask participants about their active and passive information searching, internet skills and use, perceived quality, and accessibility of different information sources were used. The full questionnaire and sources for questions can be found in the appendix.

Both online and postal versions of the questionnaire were provided. These options were offered in order to reach a wide cross section of the population, especially given that there was an increased chance that older participants would not have online access (Office for National Statistics, 2015). The online questionnaire was built and distributed via Bristol Online Surveys.

The questionnaire was reviewed for clarity by an Occupational Therapist with significant experience working in the community with people with dementia and their carers, it was then piloted with two carers of people with dementia known to the researcher in order to assess the 
content and clarity of both the online and postal versions. Following the questionnaire pilot minor changes were made to the wording and grammar of some questions.

\section{Data Analysis}

To test the first aim, descriptive statistics from questions relating to active and passive information source use were used. Spearman's Rho Correlations were calculated between demographic characteristics such as age and level of education and use if different information sources and then between which information sources were used against how participants feel about their search for information and their level of knowledge.

Frequencies were also calculated for information source preference for a range of different topics in order to try to identify if information source use depends on the topic of information required.

To test the second aim, positive, neutral and negative descriptive statistics were calculated. Spearman's Rho calculations between the information sources used and overall feelings towards those sources were calculated. Personal Likert responses for effort, frustration, quality and comprehension were combined to create a Likert scale for each respondent's information seeking (Bradburn, Sudman, \& Wansink, 2004).

The third aim was tested via open responses which were then analysed using thematic analysis. Codes relating to topics and frequencies were used to define participant preferences for information delivery. Finally this was cross referenced to findings from the first two aims to generate a discussion.

Open questions providing qualitative data entered into Nvivo10 software and thematically coded in a process of interpretive analysis (Smith \& Osborn 2007). This analysis involved initially reading the responses to gain an overview of the comments, then rereading to draw 
key points and statements from the answers to produce overarching themes. These themes were then used to enrich the results from the quantitative data.

\section{Ethical Approval}

The study was given ethical approval by the University of Warwick Biomedical and Scientific Research Ethics Committee. Study number REGO-2016-1826.

\section{RESULTS}

A total of 214 completed questionnaires were received via online $(n=197)$ and by post $(n=15)$.

Two postal replies were not included for analysis as participants indicated that their relative was now living in a residential care setting. The results and analysis are therefore based upon 212 responses.

\section{Characteristics of the Sample}

The mean age for respondents was 57 years $(\mathrm{SD}+/-10.6)$ and the mean age of the people with dementias they care for was 79 years $(\mathrm{SD}+/-12.6)$. Replies were received from all four countries of the United Kingdom: England 67\% $(n=140)$, Scotland 20\% ( $n=20)$, Wales 12\% $(25 \%)$ and Northern Ireland $1 \%(n=2)$.

$80 \%$ of respondents were female $(n=171)$ and $57 \%$ of the respondent's corresponding family member or friend with dementia were female $(n=121)$. The sample was predominantly composed of those from a white/white Irish/white other ethnic group $(n=208)$.

The majority of respondents has been educated beyond age $16(n=134)$. The largest group were educated to Postgraduate level $(n=54)$ and $n=46$ held a professional qualification. Of the cohort of respondents here $(n=177)$ had a parent with dementia and a comparatively low number were caring for a spouse $(n=24)$ or friend $(n=2)$.

The distribution of different types of dementia diagnosis amongst the friends and family of respondents were comparable to the recognised distribution of the condition, with Alzheimer's 
disease the most common $(n=99)$ followed by Vascular Dementia $(n=53)$, Frontotemporal Dementia $(n=11)$ and Dementia with Lewy Bodies $(n=11)$. The majority $(n=127)$ had been living with a diagnosis of dementia for less than 4 years, with the peak number of respondents having had a diagnosis 1-3 years ago $(n=76)$.

\section{Sources of information currently accessed}

\section{The Internet}

Only two $(0.9 \%)$ respondents did not go online to access either the World Wide Web or use email. In fact the internet was the source most commonly used by participants to actively search for information about dementia $(n=175,82 \%)$. The second most popular choice was health and social care professionals $(\mathrm{n}=112)$ as shown in Figure 1. Interestingly, although $99 \%$ $(n=210)$ of participants state that they went online to access the World Wide Web, $17 \%(n=35)$ of respondents who have the skills to access and use the internet do not then use it to search for information regarding dementia.

\section{$<$ Figure 1 about here $>$}

Age was significantly, negatively correlated with the number of times a week the internet was used (Spearman's rho, 2 tailed test $r=-0.182 \mathrm{p}=>0.01$ ) and also with the likelihood of using the internet as an information source (Spearman's rho, 2 tailed test $r=-0.145 \mathrm{p}=>0.01$ ) meaning younger people were more likely to utilise the internet for finding information.

The mean number of information sources searched actively by participants was 4.4 (SD +/2.3) with a median of 4 . Perhaps not surprisingly there was a significant, positive correlation between the number of websites used and both the number of times a week a participant accesses the internet (Spearman's rho, 2 tailed test $r=0.233 \mathrm{p}=>0.01$ ) and the likelihood of using the internet for information searching (Spearman's rho, 2 tailed test $r=0.314 \mathrm{p}=>0.01$ ). 
Most respondents (97\%) who use the World Wide Web do so at home, followed by 57\% who access the World Wide Web via a mobile device. The most common type of website used by people looking for dementia information were those produced by dementia charities $(n=173$ endorsements, $82 \%$ ). Figure 2. On average, respondents looking for information on the internet used 3.32 different types of website. There was a significant, positive correlation between the number of different types of website used and effort in finding information (Spearman's Rho two tailed test $r=0.142, p=>0.05)$. Interestingly, this means that the more websites used, the easier participants found the search for information.

\section{$<$ Figure 2 about here $>$}

When people were asked why they used the internet two themes emerged, habit and accessibility. For some, searching for information on the internet was an habitual response to a need for information. For others, the internet was used due to its immediate accessibility, it is open 24 hours a day and for some the only place they feel they can look and they are guaranteed to find information (even if it is not the information they require).

Those who use the internet more often felt were more likely to feel unable to absorb all the information offered than those who used it less (Spearman's rho, 2 tailed test. $r=-0.220 \mathrm{p}>0.01$ ).

\section{Relational Information Sources}

The most used relational information source was a GP, with 187 endorsements, followed by friends and family with 145 . Overall, there were mixed views regarding healthcare practitioners as a source of information and advice. The majority of respondents $(\mathrm{n}=152 ; 72 \%)$ had received passive information from GPs, of these $38 \%$ rated the quality of information that GPs gave as poor or very poor. This was further highlighted in the open responses where participants voiced negative feelings towards GPs as a source of information due to a lack of specific dementia knowledge or poor accessibility. 


\section{Friends and Family}

Friends and family were ranked as the most popular information source for emotional support with $66.5 \%$ of respondents indicating that they would go to friends and family first. However they rank lower than health care professionals and dementia advisors for practical advice, medication advice, and advice about how to manage memory loss and other symptoms.

\section{Support Groups}

$31 \%$ of respondents have attended a support group for carers. Of those that had not yet attended a support group, $41 \%$ stated that they would consider attending one in the future. Reasons for not considering attending a support group were, prefer other information sources $(n=4)$, it won't help $(n=3)$, I am not the main carer so not relevant to me $(n=4)$, would rather talk about other things $(n=3)$, lack of time $(n=3)$, I don't like talking to strangers $(n=2)$ and it would be depressing $(n=1)$.

\section{Passive Information Sources}

The mean number of different passive information sources which provided respondents with information was $3.5(\mathrm{SD}=+/-1.7)$ with a median of 3 (Of these passive sources Newspapers $(n=151)$, As shown in Figure 3, internet $(n=134)$ and Television $(n=139)$ were the most common ways to receive passive information).

\section{$<$ Figure 3 about here $>$}

Passive information led to further action by the majority of respondents $(n=156) .73 \%$ of respondents has used information they had received passively to go on to make changes to their lifestyle or behaviour (12\%) or seek further information (61\%). Participants were openly asked to indicate how they had either sought further information or made changes following seeing or receiving passive information (Table 1). 
The responses here are not clearly defined, a further 21 responses indicated that the individual had looked for further information but not indicated from where. It is also unclear where the overlaps of sources lie, for example it is likely that some respondents contacted charities via online methods and some dementia training courses are provided online but type of training course was not specified. Therefore it is likely that 'Used internet' scores are under reported.

\begin{tabular}{|c|c|c|c|}
\hline Response & $\begin{array}{l}\text { Number of } \\
\text { responses }\end{array}$ & How Passive information was used & Frequency \\
\hline $\begin{array}{l}\text { Yes: By seeking } \\
\text { further information }\end{array}$ & 130 & $\begin{array}{l}\text { - } \text { Contacted charities } \\
\text { - Used internet } \\
\text { - Asked health care } \\
\text { professionals for information } \\
\text { regarding: } \\
\text { O Medication } \\
\quad \text { Care services } \\
\quad \text { Financial assistance } \\
\text { - Equipment } \\
\text { - Enquired about research } \\
\text { participation } \\
\text { - Attended dementia training } \\
\text { course } \\
\text { Bought book } \\
\text { - Asked about Power of } \\
\text { Attorney }\end{array}$ & $\begin{array}{l}6 \\
10 \\
3 \\
3\end{array}$ \\
\hline $\begin{array}{l}\text { Yes: By changing } \\
\text { something }\end{array}$ & 26 & $\begin{array}{l}\text { - Began attending carer or } \\
\text { support group } \\
\text { - Changed diet } \\
\text { - Changed behaviour towards } \\
\text { loved one } \\
\text { - Actively sought out a diagnosis } \\
\text { from doctors }\end{array}$ & $\begin{array}{l}12 \\
6 \\
8 \\
3\end{array}$ \\
\hline No & 55 & & \\
\hline
\end{tabular}

Table 1 Have you ever acted upon passive information?

\section{Access and comprehension}

\section{Accessibility}

Figure 4 shows health and social care professionals were viewed as the most inaccessible sources with $55 \%$ and $45 \%$ scoring their accessibility negatively. The internet was regarded as the most accessible source of information ( $86 \%$ of respondents viewing internet accessibility positively), followed by published material (72\%) and mass media (68\%). 


\section{$<$ Figure 4 about here $>$}

A significant, positive correlation was found between perceived accessibility of health professionals and the perceived quality of GP information $(\mathrm{r}=0.233 \mathrm{p}>0.01)$. This indicates that for this population, the more accessible participants feel GPs are, the higher they rate the quality of information they give. Interestingly, this correlation was not seen between accessibility and other healthcare professionals (dementia specialist nurse, dementia consultant, other consultant, Occupational Therapist).

A positive correlation was also found between the perceived accessibility of the internet and the likelihood of internet use $\mathrm{r}=0.229 \mathrm{p}>0.01$ ).

\section{Comprehension}

The sources of information offered were largely found to be comprehensible with the least understandable sources perceived to be telephone helplines (16\% negative responses) and social care professionals (14\% negative responses) (Figure 5). The most easily comprehensible information was felt to be from charities, with $81 \%$ people responding positively and support groups with $77 \%$ of people who had used them feeling the information they provide was comprehensible. This is perhaps not surprising as many dementia support groups are run by charities therefore it is reasonable that information provided at support groups matches that provided from the charities that run them.

\section{$<$ Figure 5 about here $>$}

There was a significant, positive correlation between how comprehensible respondents found internet sources and the likelihood that they would use the internet to look for information about dementia (Spearman's rho, 2 tailed test $\mathrm{r}=0.180 \mathrm{p}=<0.01$ ). 


\section{Quality}

Figure 6 displays that when asked about their perceived quality of passive information received from several different relational sources there was less variation in perceived accessibility and the ability to comprehend information for the internet than for other sources as shown in figures 4-6.

\section{$<$ Figure 6 about here $>$}

$51 \%$ of respondents felt that the information given by friends and family was of good quality compared to only $35 \%$ for GPs and $37 \%$ for dementia nurses. Friends and family also ranked highly for accessibility with $80 \%$ ranking it as easy or very easy to access, compared with $20 \%$ for health care professionals and $33 \%$ for social care professionals.

Other carers / people with dementia were highly regarded as a source of information with $70 \%$ rating this information as good or very good. The poorest quality passive information was perceived as coming from GPs with $38 \%$ and Social Workers with $31 \%$ of respondents who had received information this way rating it poor or very poor.

\section{Information Source Preference}

$54 \%$ of respondents $(n=115)$ indicated that they agreed or strongly agreed that they felt well informed about dementia, yet, $41 \%(n=56)$ indicated that they felt they had not received enough information about living with dementia. A small yet significant link was seen between the amount of time since diagnosis and how well informed participants felt (Spearman's rho, 2 tailed test $\mathrm{r}=0.164 \mathrm{p}=>0.05)$.

The most important characteristic of an information source was described as trustworthiness $(n=128)$ followed by accessibility $(n=84)$ and able to answer specific questions $(n=86)$. The least important aspect was offering a broad range of topic $(n=77)$ followed by that which includes the experiences of others $(n=56)$. 
When asked in an open question how participants would ideally like to receive information about dementia, the most common preference was from a well-informed health professional (present in 57 replies) this could then be further broken down into Dementia specialists $(\mathrm{n}=23)$ and more general health professional responses $(n=34) .29$ respondents listed the internet as a preferred method of receiving information with participants wanting a 24 hour accessible information option. Interestingly, 24 respondents expressed wanting to be able to receive information via email. Reasons given for preferring email included being able to connect with knowledgeable professionals in a more accessible and private way.

Across both relational and non-relational sources was the desire for individualised information from sources with a good depth of knowledge and provided at the most appropriate time as reflected by Respondent 77:

"Through a human who can consolidate best practice support for my local area, taking into account my mum's situation and understanding how to help mum while she manages to stay in her own home” (Respondent 77)

Accessibility and timeliness of support was also important. Eleven respondents described their ideal information source would be more accessible and thirteen felt that they would like information in a more timely way. Here there was divided opinion as to the best way to receive information following diagnosis. Specifically, six participants felt that they would prefer more information at the point of diagnosis to help guide them. However, four respondents felt that information would be better received via regular updates or printed information that can be used as a reference when they felt they needed it and prevent them from becoming overwhelmed. 


\section{DiSCUSSION}

The three aims of this study were to investigate where people with dementia and their carers receive information and advice about living with the condition, how they feel about the available information sources and how they would like to receive information. In support for previous research (Zimmer et al. 2007; Lu \& Yuan 2011), accessibility and quality were the predisposing factors relating to information source use.

Contrary to previous studies from other conditions (Lu \& Yuan, 2011; Pecchioni \& Sparks, 2007), family and friends of those with dementia appear to approach non-relational sources first, due to their accessibility and breadth. This is also apparent in the use of passive sources of information as a platform to then seek more information about specific topics. The cursory nature of dementia information from mass media and TV serves as a brief introduction to which carers can assess the personal relevance and then seek information that is relevant to them.

Participants also express unhappiness with the lack of access to health professionals and also a perceived lack of knowledge by those professionals. Thus they lack both the quality and the accessibility needed by information seekers (Lu \& Yuan, 2011; Washington et al., 2011). Medical professionals, specifically GPs were mentioned more and offered greater influence over information seeking behaviour than any other relational information source. This underlines the importance for GPs of the ability to empower their patients to use non-relational, more easily accessible sources (Lu \& Yuan, 2011).

People with a dementia diagnosis will all have contact with healthcare professionals at some point. These professionals are expected to be both knowledgeable about dementia and be able to signpost them to appropriate services. The internet is a popular source of information but, for many, does not replace the need for face to face advice from professionals. Despite GPs representing one of the more easily accessible health professionals due to their frontline primary care role, respondents would like them to be more accessible. Participants also felt that 
the current level of information provision by GPs lacks specificity and dementia specialism, indicating that the knowledge of health professionals did not meet the expectations of participants and therefore did not address information need.

Participants who felt health professionals were more accessible also felt that they offered better quality of information. Despite this link it is unclear where the causal relationship lies. Does being able to speak to healthcare professionals (of which the GP is one) make individuals feel generally more positive about the quality of the information they are given or can receiving good quality information mitigate for perceived issues with accessibility.

One answer could lie in differences between perceived quality of passive and active information from GPs. Whilst GPs scored the lowest for quality of passive information (information provided without being specifically requested), they were viewed more positively for active information (answers to specific questions). This could indicate disconnect between what GPs believe patients need to know and what patients or carers want to know about living with the condition.

Receiving a diagnosis of dementia is stressful for both the recipient of the diagnosis and those close to them. Therefore it is possible that any information given at this time is viewed negatively due to the association with bad news or an inability to process the full situation at the time. Gauging the correct type and level of information that is required to meet individual need and stage of the condition, and then providing this in an acceptable and accessible way could hold the key to improving information provision in dementia.

The contradictory finding that people feel well-informed but also feel that they have not had enough information may point to the struggle to find information actively. It is possible that an arduous active information search when coupled with the stresses of a diagnosis of dementia has long term impact on the attitudes of the individual towards their dementia knowledge. 
Indeed, the results here indicate that family members or friends are receiving or finding information after diagnosis, as the longer the period since diagnosis, the better informed participants felt. This indicates that it is not the end result in the information search but the route to reach an appropriate level of knowledge which influences carer's perceptions of information gathering in dementia.

Contrary to previous research (Bishop et al., 2009), these results show that the ability to access the internet is widespread throughout all ages. However, there are age-related differences in the regularity of internet use and the likelihood of using the internet to look for dementia information. Although older people have the skills and equipment to enable them to use the internet, they are still less likely to consider it for information seeking. It is noteworthy that respondents who used the internet more were more likely to feel unable to take in all the information offered.

Internet sources actually scored less negatively than healthcare professionals for accessibility. However, research has shown that internet health sources are extremely variable both in their quality and usability (Anderson et al., 2009). The results here show charities and governmentrun websites are those most commonly used to access dementia information, which perhaps represents efforts by information seekers to diminish uncertainty regarding the quality of online information by using known, trusted sites.

Respondents stated that they trusted the internet and found the information credible, which is in disagreement with Sweet (2013) who found that the internet was not perceived as a reputable source due to its breadth and difficulty judging the quality of its content. Pecchioni \& Sparks (2007) discovered that family members of those with cancer found the internet more useful than the patients themselves. This, they hypothesised, could be due to family members having less access to health professionals and therefore needing to seek information from elsewhere. 
This is particularly pertinent for family and friends of those with dementia because there is sometimes a reluctance by those in the early stages to accept the diagnosis. Family members are often unable to attend healthcare appointments or be able to ask medical staff questions directly due to confidentiality.

Health and social care professionals were a preferred first point of advice, before the internet for information on medication, memory and other symptoms. Therefore, the internet as a new source of information is not taking the place of more traditional sources but rather used as a supplemental information source used when relational sources cannot be accessed. This supports the findings of Lu and Yuan (2011), that individuals would prefer information directly from another person but they are forced to other, non-relational sources due to lack of appropriate people to ask. It is conceivable that when people are unable to access their first choice of information source they become discontented with information provision as a whole.

The internet was also used prior to appointments with health care professionals so respondents could be better prepared. This relationship appears to be bidirectional as other studies have shown that family members also use online sources to clarify terms used by clinicians (Nagler et al., 2010; Pecchioni \& Sparks, 2007).

This research lends weight to the suggestions by Harland \& Bath (2008), that carers of those with dementia may use differing information sources for different types of information and support. Significant others of people with dementia turn to family and friends first for emotional support which is perhaps expected. What is unclear is whether the severity of dementia symptoms affects this choice, and whether the need for information and choice of source change as the condition progresses. Progression of dementia symptoms means greater time spend in caring tasks, which means less time is available for information seeking, but may increase the carers information and support needs. 
Participants in this study expressed a desire for both tacit and explicit knowledge. The National guidelines regarding information provision by healthcare professionals covers the areas of treatment, services and disease progression (National Institute for Health and Care Excellence, 2010). These topics lie at the explicit end of the information continuum and therefore, information provision following diagnosis may not be providing suitable levels of tacit knowledge to meet the expectations of people with dementia and their relatives and friends.

Data here also reinforce another common finding in information literature the concept that one size doesn't fit all. Indeed previous reviews of information services found the same (Koenig, Steiner, \& Pierce, 2011; Suhonen et al., 2015; Washington et al., 2011). However, there are financial difficulties in providing individualised information.

Face-to-face contact perhaps offers the most straightforward option, where carers can ask individual questions and therefore tailor the information they are seeking. Relational professional contact comes at a financial cost for example the cost of a GP face-to-face consultation is $₫ 3.90$ per minute. The average GP appointment time in the UK is 9.22 minutes which means the average UK GP appointment is $£ 36$ (Curtis \& Burns, 2016). However the cost of a GP telephone triage appointment is less than half the costs at $£ 14.40$. The costs of a visit to NHS Choices (the NHS online information platform) costs 1.8 pence.

Cost implications of service provision are apparent in specialist dementia services, for example the Admiral Nurse service, provides support to people living with dementia and their families in the UK. However their service is confined to those living within specific NHS trusts, working for specific employers or connected with other charities (Dementia UK, 2018). Therefore individuals living outside these criteria cannot access this specific source of information and advice. These geographic funding issues are not confined to the Admiral Nursing service and exist due to differences in the funding and commissioning of healthcare services. 
To provide personalised information it is first necessary to accurately assess individual information need (Koenig et al., 2011; Suhonen et al., 2015). Currently there remains no validated, reliable or practical assessment techniques for health care professionals to quickly and effectively assess information preferences and need for this population.

\section{Limitations}

Dementia charities are a widely used source of information about dementia but the charities themselves make use of a variety of information platforms to provide information, therefore it is reasonable to consider that scores relating to internet use, support groups, telephone helplines and dementia advisors are all connected.

The majority of responses were made online which naturally creates bias towards those who can use the internet as a resource. Although efforts were made to advertise and provide the survey by other means, the results may therefore still be biased.

Whilst the survey asked participants about the length of time since dementia diagnosis of their friend or family member, the severity of their dementia symptoms was not assessed. There is a possibility that the sources of information used correlates to the severity of dementia symptoms faced as this may also impact on the amount of time available to carers to spend seeking information and the breadth of information required.

This study did not seek to explore which factors were associated with better quality sources of information. Further exploration of this could shed light on which particular aspects of the interaction between information seeker and information provider were linked to the perception of poor quality and how this could be mitigated.

A further research project is currently being designed, which aims to investigate the knowledge of healthcare professionals, with particular reference to GPs, in order to discover where they 
find dementia related information and what is the process of knowledge dissemination between these practitioners and people living with dementia.

\section{Conclusion}

These results highlight that good quality and trustworthy internet sources are being widely used by people with family members or friends with dementia, however there remains an important need for health professionals to be well informed and accessible to provide good quality dementia information as this may influence how well-informed carers feel over the whole disease progression.

Many sources of information provide advice and information for people caring for a relative or friend with dementia but they are not equally useful to this population. The main determinants for information source use are accessibility and the ability of the source to address specific individualised queries. However this data represents a discrepancy between the sources of information that are being used and where family and friends of individuals with dementia would most like their information to come from.

The selection of the internet as the most used form of information is not due to its ability to provide quality or individualised information, but in the absence of the preferred source of information (knowledgeable GP or dementia specific health care professionals) the internet represents a quick, accessible resource that can provide a large quantity of information.

\section{Future research}

There is a need for integrated multiple sources of dementia information which can match individual need. Further research is needed to establish whether individual information preferences and need can be quickly and reliably assessed. This would allow healthcare providers to commission the design and creation of targeted and personalised information. 
Given the preference of individuals for relational information but the relative inaccessibility of this type of information, ways in which technology can be used to replicate relational information experience need to be explored. This provides an interesting research direction in the area of human-centric interaction design.

\section{Declaration of Conflicting Interests}

The Authors declare that there is no conflict of interest

\section{Funding}

This research received no specific grant from any funding agency in the public, commercial, or not-for-profit sectors. 


\section{REFERENCES}

Allen, F., Cain, R., \& Meyer, C. (2017). How people with dementia and their carers adapt their homes. A qualitative study. Dementia, 1471301217712294.

https://doi.org/10.1177/1471301217712294

Altizer, K. P., Grzywacz, J. G., Quandt, S. A., Bell, R., \& Arcury, T. A. (2014). A Qualitative Analysis of How Elders Seek and Disseminate Health Information. Gerontology \& Geriatrics Education, 35(4), 337-353 17p.

https://doi.org/10.1080/02701960.2013.844693

Anderson, K. A., Nikzad-Terhune, K. A., \& Gaugler, J. E. (2009). A Systematic Evaluation of Online Resources for Dementia Caregivers. Journal of Consumer Health on the Internet, 13(1), 1-13. https://doi.org/10.1080/15398280802674560

Bishop, M., Frain, M. P., Espinosa, C. T., \& Stenhoff, D. M. (2009). Sources of information about multiple sclerosis: Information seeking and personal, demographic, and MS variables. Journal of Vocational Rehabilitation, 31(2), 107-117. Retrieved from 10.3233/JVR-2009-0479

Craig, D., \& Strivens, E. (2016). Facing the times: A young onset dementia support group: FacebookTM style. Australasian Journal on Ageing, 35(1), 48-53. https://doi.org/10.1111/ajag.12264

Curtis, L., \& Burns, A. (2016). Unit Costs of Health and Social Care 2016. Canterbury. Retrieved from http://www.pssru.ac.uk/project-pages/unit-costs/2016/index.php

Dementia UK. (2018). Find a local Admiral Nurse team. Retrieved April 11, 2018, from https://www.dementiauk.org/get-support/find-an-admiral-nurse/

Dutta-Bergman, M. J. (2004). Complementarity in Consumption of News Types Across Traditional and New Media. Journal of Broadcasting \& Electronic Media, 48(1), 41-60. https://doi.org/10.1207/s15506878jobem4801_3

Fischer, S. H., David, D., Crotty, B. H., Dierks, M., \& Safran, C. (2014). Acceptance and use of health information technology by community-dwelling elders. International Journal of Medical Informatics, 83(9), 624-635. https://doi.org/http://dx.doi.org/10.1016/j.ijmedinf.2014.06.005

Foster, D. (2016). "Keep complaining til someone listens": Exchanges of tacit healthcare knowledge in online illness communities. Social Science \& Medicine, 166, 25-32. https://doi.org/http://dx.doi.org/10.1016/j.socscimed.2016.08.007

Harland, J. A., \& Bath, P. A. (2008). Understanding the information behaviours of carers of people with dementia: a critical review of models from information science. Aging \& Mental Health, 12(4), 467-477. Retrieved from http://search.ebscohost.com/login.aspx?direct=true \&db=cin20\&AN=2010076077\&site= ehost-live

Johnson, D., \& Case, D. (2012). Health Information Seeking. New York: Peter Lang.

Koenig, K. N., Steiner, V., \& Pierce, L. L. (2011). Information Needs of Family Caregivers of Persons With Cognitive Versus Physical Deficits. Gerontology \& Geriatrics Education, 
32(4), 396-413 18p. https://doi.org/10.1080/02701960.2011.611713

Lu, L., \& Yuan, Y. C. (2011). Shall I Google it or ask the competent villain down the hall? The moderating role of information need in information source selection. Journal of the American Society for Information Science \& Technology, 62(1), 133-145 13p. https://doi.org/10.1002/asi.21449

Nagler, R. H., Romantan, A., Kelly, B. J., Stevens, R. S., Gray, S. W., Hull, S. J., ... Hornik, R. C. (2010). How Do Cancer Patients Navigate the Public Information Environment? Understanding Patterns and Motivations for Movement Among Information Sources. Journal of Cancer Education, 25(3), 360-370. https://doi.org/10.1007/s13187-010-00545

National Institute for Health and Care Excellence. (2010). Dementia : support in health and social.

National Institutes of Health, \& Services, U. S. D. of H. and H. (2014). Health Information National Trends Survey, 1-9. Retrieved from http://hints.cancer.gov/docs/Instruments/HINTS_4_Cycle_4_English_Annotated_Form.p df

Office for National Statistics. (2015). Internet Access - Households and Individuals 2015. Retrieved January 5, 2016, from http://www.ons.gov.uk/ons/dcp171778_412758.pdf

Pecchioni, L. L., \& Sparks, L. (2007). Health Information Sources of Individuals With Cancer and Their Family Members. Health Communication, 21(2), 143-151. https://doi.org/10.1080/10410230701307162

Pettigrew, K. (2000). Lay Information Provision in Community Settings: How Community Health Nurses Disseminate Human Services Information to the Elderly. The Library Quarterly: Information, Community, Policy, 71(1), 47-85. Retrieved from http://0www.jstor.org.pugwash.lib.warwick.ac.uk/stable/4309399?seq=28\#page_scan_tab_cont ents

Polanyi, M. (1983). The Tacit Dimension. Gloucester: Peter Smith.

Robinson, A., Elder, J., Emden, C., Lea, E., Turner, P., \& Vickers, J. (2009). Information pathways into dementia care services: family carers have their say. Dementia (14713012), 8(1), 17-37 21p. Retrieved from http://search.ebscohost.com/login.aspx?direct=true \&db=cin20\&AN=105493860\&site=e host-live

Sharit, J., Hernandez, M. A., Czaja, S., \& Pirolli, P. (2008). Investigating the Roles of Knowledge and Cognitive Abilities in Older Adult Information Seeking on the Web. ACM Transactions on Computer-Human Interaction, 15(1). Retrieved from http://0delivery.acm.org.pugwash.lib.warwick.ac.uk/10.1145/1360000/1352785/a3sharit.pdf?ip $=137.205 .50 .42 \& i d=1352785 \&$ acc $=$ ACTIVE SERVICE\&key=BF07A2EE685417C5.487CE3B0BD082C1B.4D4702B0C3E38B35.4D4702B0 C3E38B35\&CFID $=597329950 \& C F T O K E N=94109496 \& \_\mathrm{acm} \_=145976$

Smith, Jonathan, A., \& Osborn, M. (2007). Interpretative Phenomenological Analysis. In Qualitative Psychology: A Practical Guide to Research Methods (Second, pp. 53-80). 
London: SAGE Publications.

Suhonen, R., Stolt, M., Koskenniemi, J., \& Leino-Kilpi, H. (2015). Right for knowledge - the perspective of significant others of persons with memory disorders. Scandinavian Journal of Caring Sciences, 29(1), 83-92. https://doi.org/10.1111/scs.12132

Sweet, S. N., Perrier, M.-J., Podzyhun, C., \& Latimer-Cheung, A. E. (2013). Identifying physical activity information needs and preferred methods of delivery of people with multiple sclerosis. Disability \& Rehabilitation, 35(24), 2056-2063 8p.

https://doi.org/10.3109/09638288.2013.800915

Washington, K. T., Meadows, S. E., Elliott, S. G., \& Koopman, R. J. (2011). Information needs of informal caregivers of older adults with chronic health conditions. Patient Education \& Counseling, 83(1), 37-44 8p. https://doi.org/10.1016/j.pec.2010.04.017

Zimmer, J. C., Henry, R. M., \& Butler, B. S. (2007). Determinants of the Use of Relational and Nonrelational Information Sources. Journal of Management Information Systems, 24(3), 297-331. https://doi.org/10.2753/MIS0742-1222240310 


\begin{tabular}{|c|c|c|c|c|c|c|c|}
\hline \multicolumn{8}{|c|}{ APPENDIX } \\
\hline No. & Survey question & Source & $\begin{array}{c}\text { Question } \\
\text { type }\end{array}$ & Sample & RQ1 & RQ2 & RQ3 \\
\hline 1. & Consent & N/A & Screening & & & & \\
\hline 2. & $\begin{array}{l}\text { Do you have a diagnosis of dementia or are you a carer } \\
\text { for a relative or friend with dementia? }\end{array}$ & $\mathrm{N} / \mathrm{A}$ & Screening & & & & \\
\hline 3. & $\begin{array}{l}\text { How long ago did your family member/friend receive a } \\
\text { diagnosis of dementia? }\end{array}$ & N/A & MC SA & $\checkmark$ & & & \\
\hline $3 b$. & $\begin{array}{l}\text { How would you describe your relationship with your relative / friend with } \\
\text { dementia? }\end{array}$ & & Open & $\checkmark$ & & & \\
\hline 3c. & Would you describe yourself as? (ethnicity) & ONS & MC SA & $\checkmark$ & & & \\
\hline $3 \mathrm{~d}$. & Would you describe your relative or friend with dementia as? (ethnicity) & ONS & MC SA & $\checkmark$ & & & \\
\hline $3 \mathrm{e}$. & Gender of respondent & ONS & MC SA & $\checkmark$ & & & \\
\hline $3 \mathrm{f}$ & Gender of relative or friend with dementia & ONS & MC SA & $\checkmark$ & & & \\
\hline 4. & What type of dementia has your relative/friend been diagnosed with? & & MC SA & $\checkmark$ & & & \\
\hline 5. & Age of respondent and friend/family member with dementia & N/A & Open & $\checkmark$ & & & \\
\hline $6 . \mathrm{a}$ & $\begin{array}{l}\text { Which of the following best describes the highest level of education you have } \\
\text { completed? }\end{array}$ & & MC SA & $\checkmark$ & & & \\
\hline 6.b. & $\begin{array}{l}\text { Which of the following best describes the highest level of education your relative } \\
\text { or friend with dementia has completed? }\end{array}$ & & MC SA & $\checkmark$ & & & \\
\hline 7. & Country of residence & ONS & MC SA & $\checkmark$ & & & \\
\hline 8. & $\begin{array}{l}\text { From which of the following people have you been offered passive information } \\
\text { regarding dementia and how would you rate the information that they provide? }\end{array}$ & Literature & Likert & & $\checkmark$ & $\checkmark$ & \\
\hline 9. & $\begin{array}{l}\text { Please indicate if you have ever noticed this type of information from any of the } \\
\text { following }\end{array}$ & Literature & MC MA & & $\checkmark$ & & \\
\hline 10.a. & $\begin{array}{l}\text { Have you ever acted on the information that you have seen either by seeking further } \\
\text { information or changing something? }\end{array}$ & Literature & $\mathrm{MC}$ & & $\checkmark$ & & \\
\hline 10.a.i & Please explain how & & Open Qual & & $\checkmark$ & & \\
\hline 11. & Have you actively searched for information about dementia? & Literature & $\mathrm{Y} / \mathrm{N}$ & & $\checkmark$ & & \\
\hline 11.a. & $\begin{array}{l}\text { From which of the following places have you looked or asked for information about } \\
\text { dementia? }\end{array}$ & Literature & MC MA & & $\checkmark$ & & \\
\hline 11.b. & $\begin{array}{l}\text { Based on your experiences of seeking information about dementia, how much do } \\
\text { you agree or disagree with the following statements? }\end{array}$ & $\begin{array}{l}\text { HINTS } \\
\text { survey }\end{array}$ & Likert & & & $\checkmark$ & \\
\hline
\end{tabular}




\begin{tabular}{|c|c|c|c|c|c|}
\hline 12. & Please indicate how much you agree/disagree with the following statements & $\begin{array}{c}\text { HINTS } \\
\text { survey }\end{array}$ & Likert & $\checkmark$ & $\checkmark$ \\
\hline 13. & $\begin{array}{l}\text { Do you attend or have you ever attended a support group for carers or people living } \\
\text { with dementia? }\end{array}$ & $\begin{array}{l}\text { Previous } \\
\text { Research }\end{array}$ & $\mathrm{Y} / \mathrm{N}$ & $\checkmark$ & \\
\hline 13.a. & Which groups did/do you attend? & $\begin{array}{l}\text { Previous } \\
\text { Research }\end{array}$ & Open & $\checkmark$ & \\
\hline 13.b. & Would you consider attending a group in the future? & $\begin{array}{l}\text { Previous } \\
\text { Research }\end{array}$ & $\mathrm{Y} / \mathrm{N}$ & $\checkmark$ & \\
\hline 13.b.i. & Why not? & $\begin{array}{l}\text { Previous } \\
\text { Research }\end{array}$ & Open Qual & $\checkmark$ & $\checkmark$ \\
\hline 14. & Do you own or have access to any of the following? & $\begin{array}{l}\text { HINTS } \\
\text { survey }\end{array}$ & MC MA & $\checkmark$ & \\
\hline 15. & Do you go online: emails & $\begin{array}{l}\text { HINTS } \\
\text { survey }\end{array}$ & $\mathrm{Y} / \mathrm{N}$ & $\sqrt{ }$ & \\
\hline 16. & Do you go online: WWW & $\begin{array}{l}\text { HINTS } \\
\text { survey }\end{array}$ & $\mathrm{Y} / \mathrm{N}$ & $\checkmark$ & \\
\hline 16.a & Internet where? & $\begin{array}{l}\text { HINTS } \\
\text { survey }\end{array}$ & MC MA & $\checkmark$ & \\
\hline 16.a.ii & Internet how often? & $\begin{array}{c}\text { HINTS } \\
\text { survey }\end{array}$ & MC SA & $\checkmark$ & \\
\hline 16.a.iii & $\begin{array}{l}\text { If you have looked on the internet for information, which of the following types of } \\
\text { website have you used when looking for dementia information? }\end{array}$ & Literature & MC MA & $\checkmark$ & \\
\hline 16.a.iv & $\begin{array}{l}\text { If you want to find out about an aspect of living with dementia, how likely are you } \\
\text { to look for advice on the internet? }\end{array}$ & $\begin{array}{l}\text { Previous } \\
\text { research }\end{array}$ & Likert & $\checkmark$ & \\
\hline 16.a.v & Why? & $\begin{array}{l}\text { Previous } \\
\text { research }\end{array}$ & Open & $\checkmark$ & \\
\hline 17. & $\begin{array}{l}\text { If you do not go online to access the Internet or World Wide Web please tell us } \\
\text { why? }\end{array}$ & $\begin{array}{l}\text { HINTS } \\
\text { survey }\end{array}$ & MC MA & $\checkmark$ & \\
\hline 18. & $\begin{array}{l}\text { In general how much do you trust information about dementia from the following } \\
\text { sources? }\end{array}$ & Literature & Likert & & $\checkmark$ \\
\hline 19. & $\begin{array}{l}\text { In general how understandable do you find the information provided by the } \\
\text { following information sources? }\end{array}$ & Literature & Likert & & $\checkmark$ \\
\hline 20. & In general how easy to access do you find the following sources of information? & Literature & Likert & & $\checkmark$ \\
\hline
\end{tabular}




\begin{tabular}{|c|c|c|c|c|c|c|c|}
\hline $21 . \mathrm{a}$ & $\begin{array}{l}\text { Where would you first seek information on the following and what other sources } \\
\text { would you use? } \\
\text { Medication }\end{array}$ & Literature & $\begin{array}{c}\mathrm{MC} \\
\mathrm{MA} / \mathrm{SA}\end{array}$ & & $\sqrt{ }$ & & \\
\hline 21.b. & Memory loss? & Literature & $\begin{array}{c}\mathrm{MC} \\
\mathrm{MA} / \mathrm{SA}\end{array}$ & & $\checkmark$ & & \\
\hline 21.c. & Symptom? & Literature & $\begin{array}{c}\mathrm{MC} \\
\mathrm{MA} / \mathrm{SA}\end{array}$ & & $\checkmark$ & & \\
\hline 21.d. & Equipment and living aids? & Literature & $\begin{array}{c}\mathrm{MC} \\
\mathrm{MA} / \mathrm{SA}\end{array}$ & & $\checkmark$ & & \\
\hline 21.e. & Emotional support? & Literature & $\begin{array}{c}\mathrm{MC} \\
\mathrm{MA} / \mathrm{SA}\end{array}$ & & $\checkmark$ & & \\
\hline 21.f. & Practical advice? & Literature & $\begin{array}{c}\mathrm{MC} \\
\mathrm{MA} / \mathrm{SA}\end{array}$ & & $\checkmark$ & & \\
\hline 22. & $\begin{array}{l}\text { Overall, how confident are you that you can access appropriate dementia } \\
\text { information when you need it? }\end{array}$ & $\begin{array}{l}\text { Previous } \\
\text { Research }\end{array}$ & Likert & & $\checkmark$ & & \\
\hline 23. & In an ideal world, how would you like to receive information about dementia? & $\begin{array}{l}\text { Previous } \\
\text { Research }\end{array}$ & Open & & & & $\checkmark$ \\
\hline 23.a. & $\begin{array}{l}\text { From your experiences, how close to the ideal do you feel the current sources of } \\
\text { information are? }\end{array}$ & $\begin{array}{l}\text { Previous } \\
\text { Research }\end{array}$ & Likert & & & & $\checkmark$ \\
\hline 23.a.i & Why is this? & $\begin{array}{l}\text { Previous } \\
\text { Research }\end{array}$ & Open & & & $\checkmark$ & $\checkmark$ \\
\hline 24. & $\begin{array}{l}\text { Which of these factors do you regard as the most important when considering a } \\
\text { source of advice about living with dementia, and which is the least important? }\end{array}$ & Literature & MC SA & & & & $\checkmark$ \\
\hline 25. & $\begin{array}{l}\text { Finally, is there anything else about sources of dementia information that you would } \\
\text { like us to know? }\end{array}$ & N/A & Open & $\checkmark$ & $\checkmark$ & $\checkmark$ & $\sqrt{ }$ \\
\hline
\end{tabular}

$\underline{\text { Key }}$

MC SA $=$ Multiple Choice Single Answer

MC MA = Multiple Choice Multiple Answer

$\mathrm{Y} / \mathrm{N}=\mathrm{Yes}, \mathrm{No}$, Not sure

Previous Research $=$ Derived from evidence from previous study (Allen et al., 2017)

HINTS Survey $=$ Question take from the U.S. Health Information National Trends Survey

Literature $=$ Question derived from previous published research 
RQ1: Where do family and friends of those with dementia currently access information regarding dementia?

RQ2: How accessible, credible and comprehensible do family and friends of those with dementia consider the available sources of information?

RQ3: How would family and friends of those with dementia like to receive information? 


\section{Seeking relational information sources in the digital age: A study into information source preferences among family and friends of those with dementia}

Figures

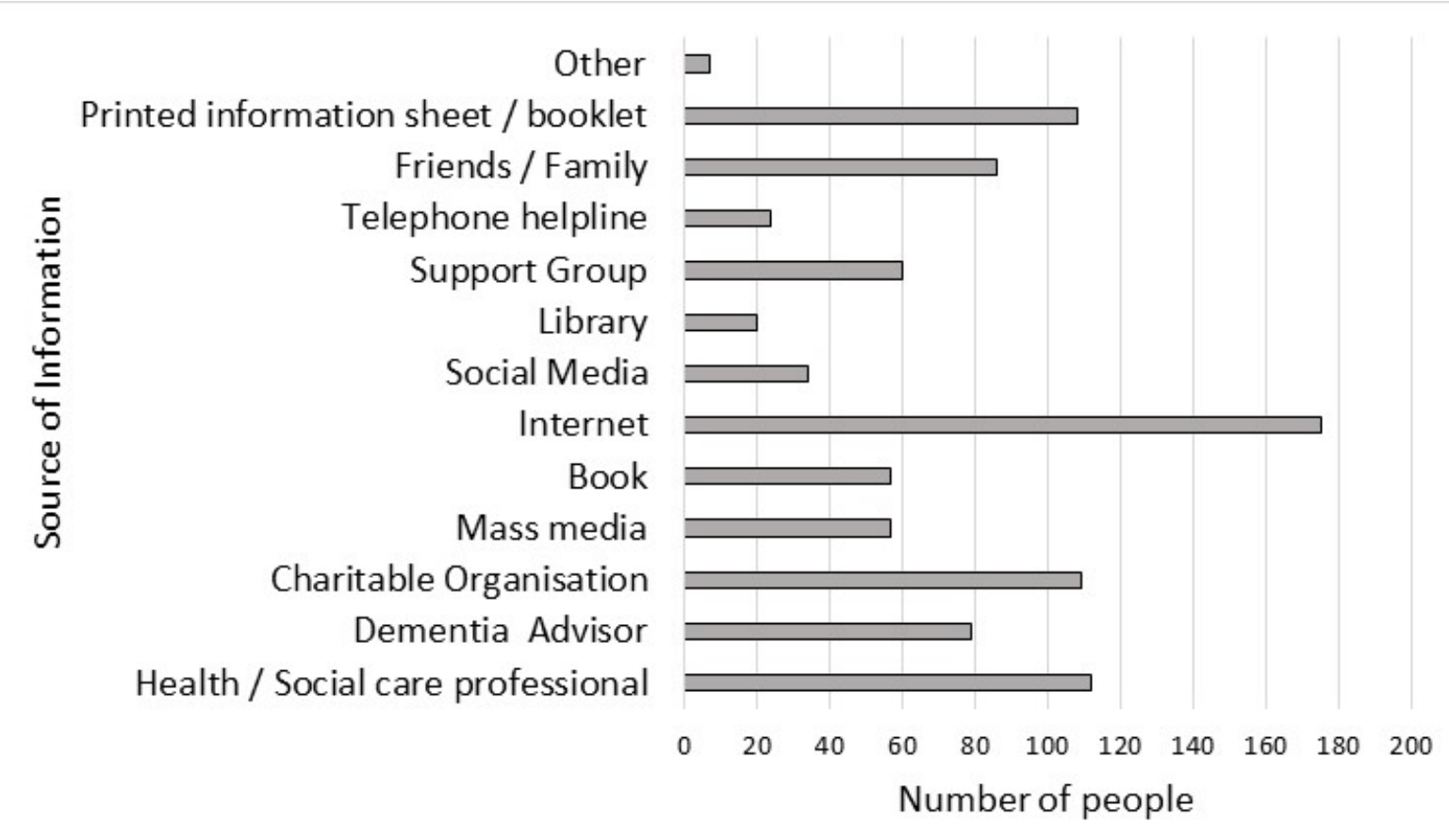

Figure 1. Sources actively searched for dementia information

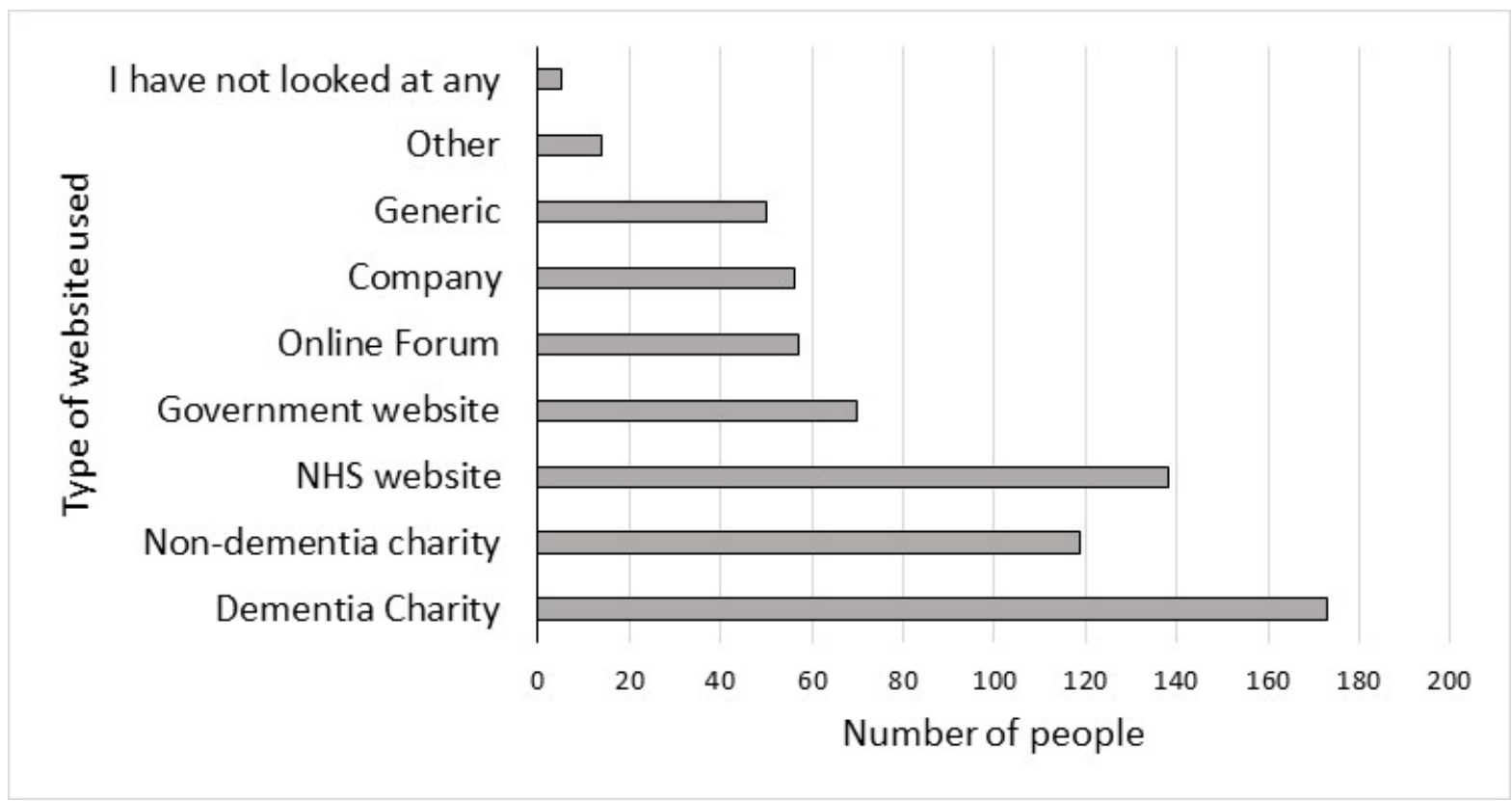

Figure 2. Types of website used for dementia information 


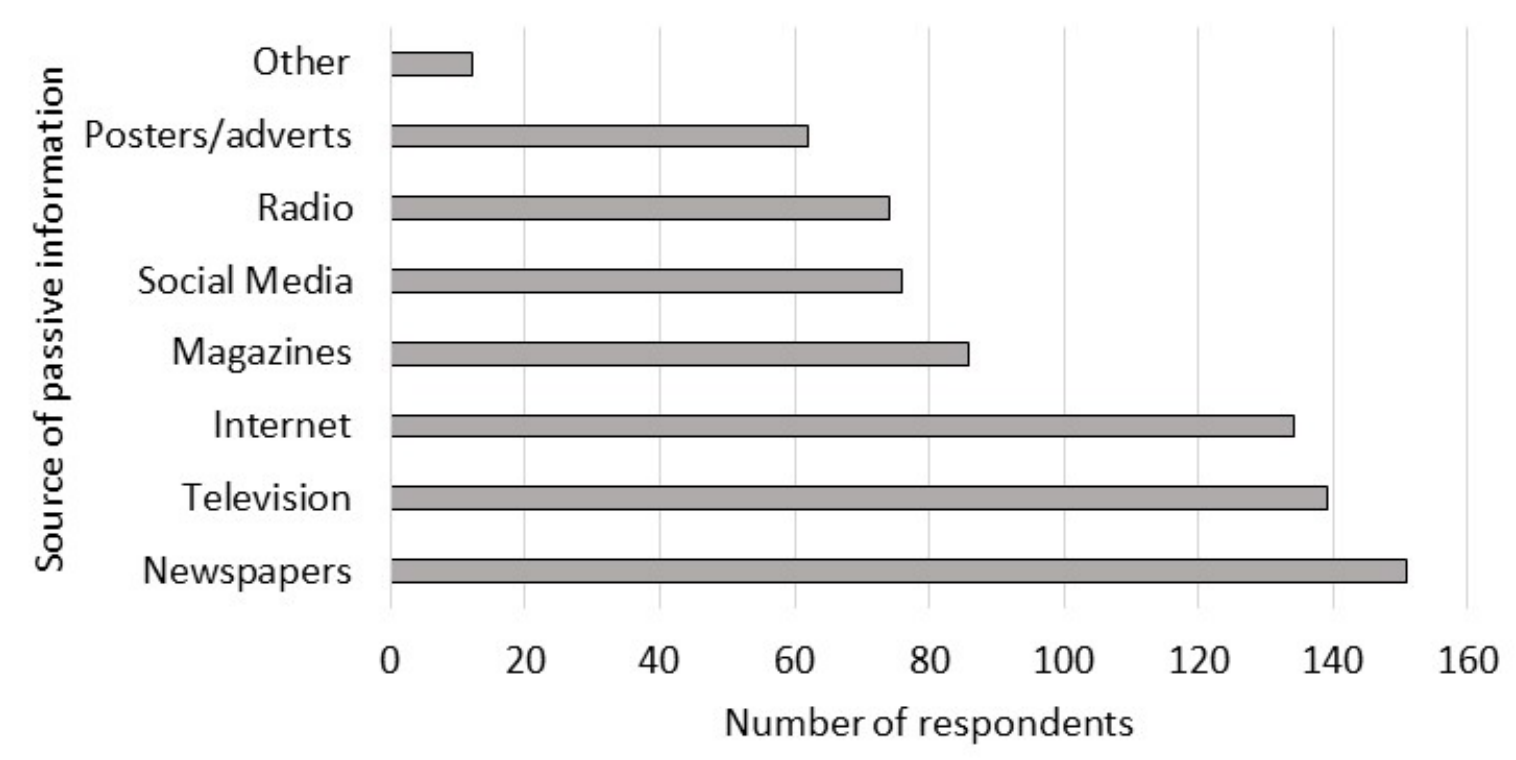

Figure 3. Sources of passive information for dementia

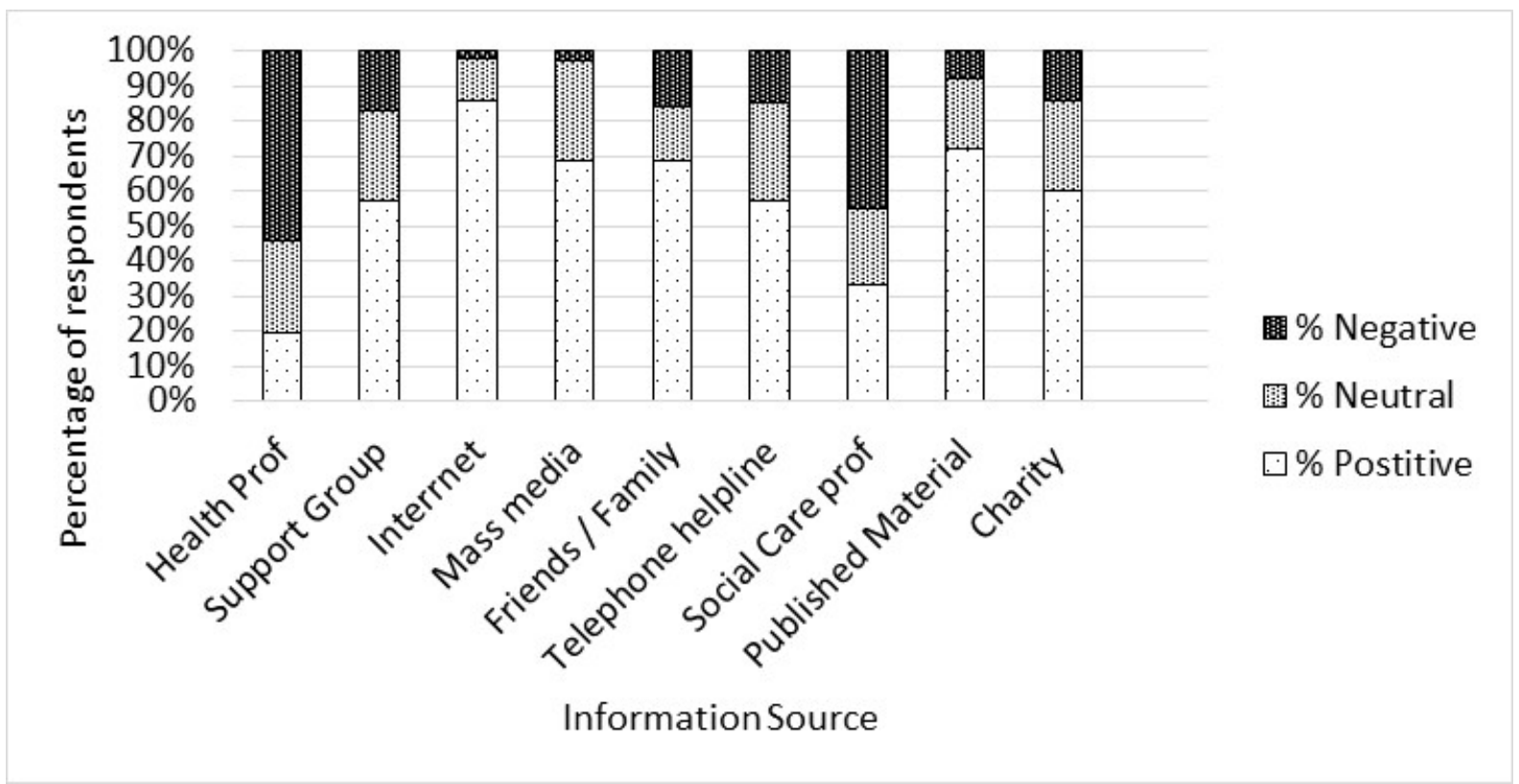

Figure 4. Perceived Accessibility of information sources 


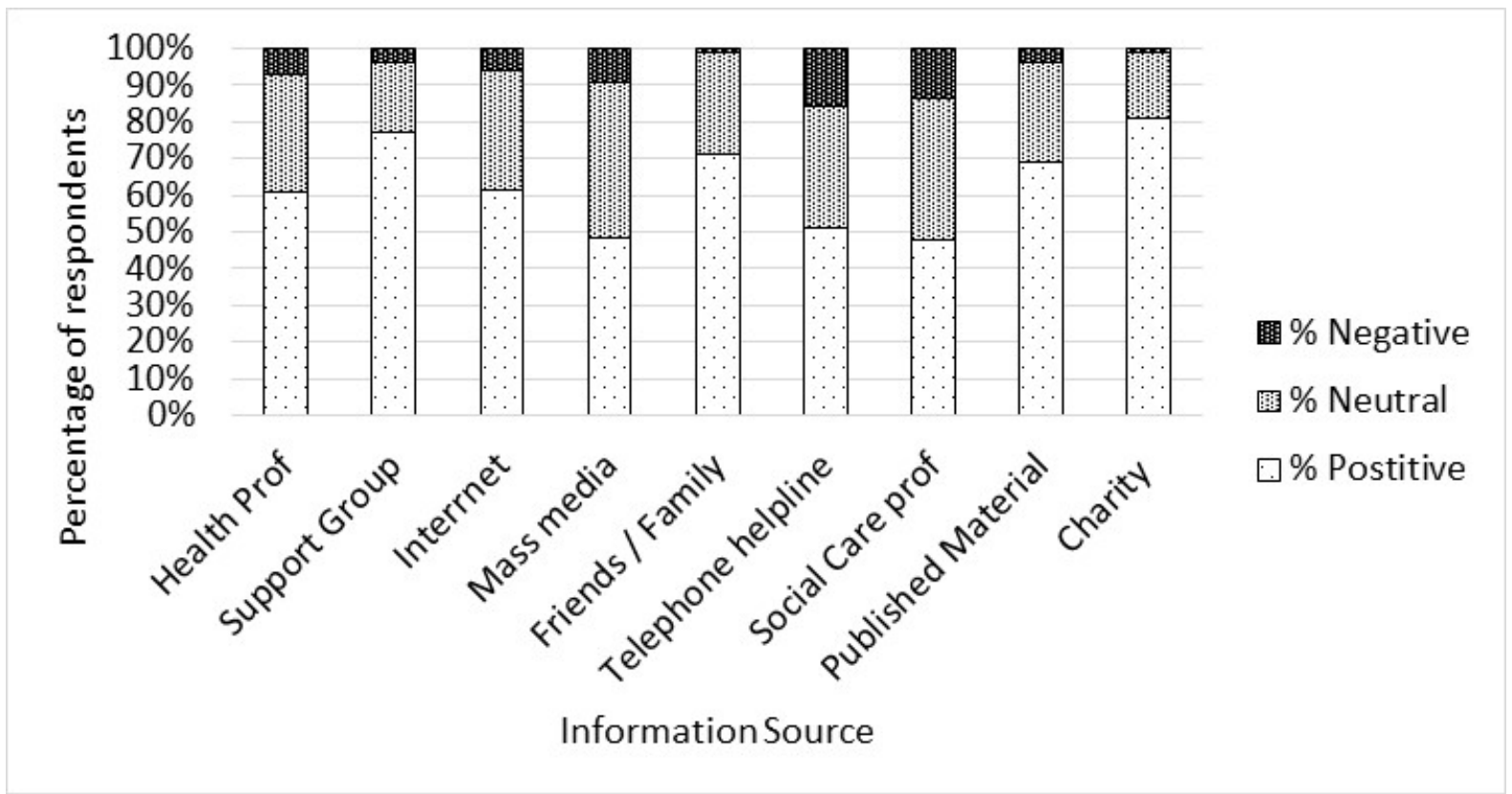

Figure 5. Perceived comprehension of information sources

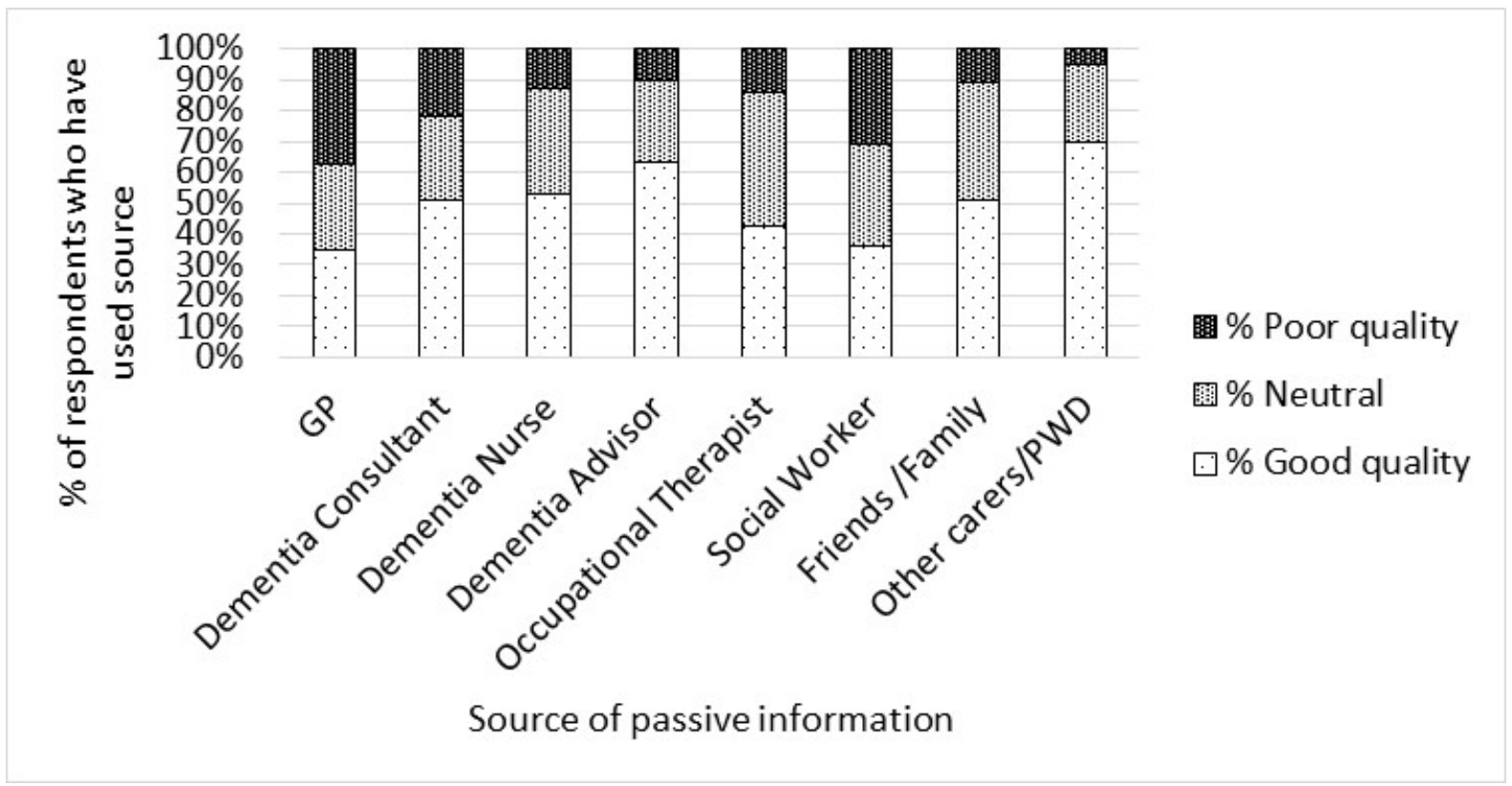

Figure 6. Perceived quality of passive information provided by relational sources 